Thorax, 1979, 34, 127-129

\title{
Myocardial sarcoidosis complicated by mural thrombosis
}

\author{
JAMES W WYNNE, ${ }^{1}$ GENE G RYERSON, AND JOSEPH DALOVISIO \\ From the Departments of Medicine (Division of Pulmonary Medicine), and Anesthesiology, \\ University of Florida, Gainesville, Florida, USA
}

Ventricular mural thrombosis, a frequent complication of the idiopathic cardiomyopathies, is rarely reported to occur in sarcoidosis. We report a patient with fatal myocardial sarcoidosis who presented with recurrent arrhythmias and unexplained pleural effusion. Post-mortem examination showed a pulmonary embolus and a mural thrombus of the right ventricle.

\section{Case report}

A 30-year-old black woman was diagnosed as having sarcoidosis on the basis of a lymph node biopsy six years before admission. During that time the patient received no treatment, and did well until one month before admission, when she developed night sweats, fever, and easy fatiguability. One week before admission she experienced nausea, vomiting, and abdominal pain, and she was admitted to another hospital. A lymph node biopsy at that hospital showed confluent non-caseating granulomas. She was then transferred to Shands Teaching Hospital for evaluation of cardiac arrhythmias and right pleural effusion.

On admission the patient was in no distress. Her temperature was $39^{\circ} \mathrm{C}\left(102 \cdot 2^{\circ} \mathrm{F}\right)$; blood pressure, $100 / 70 \mathrm{mmHg}$; pulse rate, 90 beats $/ \mathrm{min}$, with frequent premature beats; and respiratory rate, $25 / \mathrm{min}$. Dullness to percussion, decreased fremitus, and decreased breath sounds were present at the right lung base as well as bibasilar inspiratory crackles. Cardiac examination was with normal limits except for frequent premature beats. The spleen was palpable, and lymphadenopathy was present.

Haematocrit was $45 \%$, haemoglobin, $15 \mathrm{~g} /$ $100 \mathrm{ml}$; white cell count, $49000 / \mathrm{mm}^{3}$ with $66 \%$ polymorphonuclear cells, $11 \%$ band forms, $18 \%$ lymphocytes, $3 \%$ monocytes, and $2 \%$ eosinophils. Serum alkaline phosphatase was $510 \mathrm{IU} / 1$ (normal

'Supported in part by the Public Service Pulmonary Academic Award KO7 HL00122 from the National Heart and Lung Institute.
30-85); amylase, 188 Somogyi units (normal 60160); LDH, $258 \mathrm{IU} / 1$ (normal 110-245); AST, $52 \mathrm{IU} / 1$ (normal 10-40); total protein, $6.3 \mathrm{~g}$ / $100 \mathrm{ml}$; albumin, $2.9 \mathrm{~g} / 100 \mathrm{ml}$; and calcium, $8.3 \mathrm{mg} / 100 \mathrm{ml}$. Chest radiograph showed bilateral hilar and paratracheal adenopathy, extensive interstitial infiltrates, and a large right pleural effusion with a pseudotumour in the minor fissure. An electrocardiogram showed multiple premature atrial contractions, pronounced right axis deviation, deep T-wave inversion in leads $I, A V L$, and $\mathrm{V}_{2}$ to $\mathrm{V}_{6}$.

Shortly after admission pleural aspiration showed 6400 red cells $/ \mathrm{mm}^{3}$ and 1600 white cells $/ \mathrm{mm}^{3} \quad(70 \%$ lymphocytes and $30 \%$ polymorphonuclear cells) with a total protein of $2.3 \mathrm{~g} / 100 \mathrm{ml}$; LDH, $117 \mathrm{IU} / 1$; and glucose, $151 \mathrm{mg} / 100 \mathrm{ml}$. On the second hospital day the patient had an episode of supraventricular tachycardia in association with a temperature spike of $39.8^{\circ} \mathrm{C}\left(103.6^{\circ} \mathrm{F}\right)$. Her rhythm converted to sinus rhythm spontaneously. On the third hospital day the patient was found dead.

Post-mortem examination showed non-caseating granulomas in the liver, spleen, lymph nodes, and the upper lobes of both lungs. Examination of the right lower lobe showed a recent pulmonary embolus with haemorrhagic infarction. The right pleural space contained $300 \mathrm{ml}$ serosanguineous fluid. Except for slight ventricular dilatation, the heart was not enlarged and weighed $260 \mathrm{~g}$. There was diffuse granulomatous involvement of the left ventricle and entrapment of the atrioventricular conducting tissue. An organised mural thrombus was present in the right ventricle (see figure). The thrombus was not overlying or adjacent to any area of granulomatous myocardial involvement; however, disruption of muscle fibres, fibrosis, and thickening of the endocardium could be seen where the clot was densely adherent to the ventricular wall. Special stains of all tissue for acid-fast and fungal organisms were negative, as were cultures of pleural fluid for tuberculosis and fungi. 


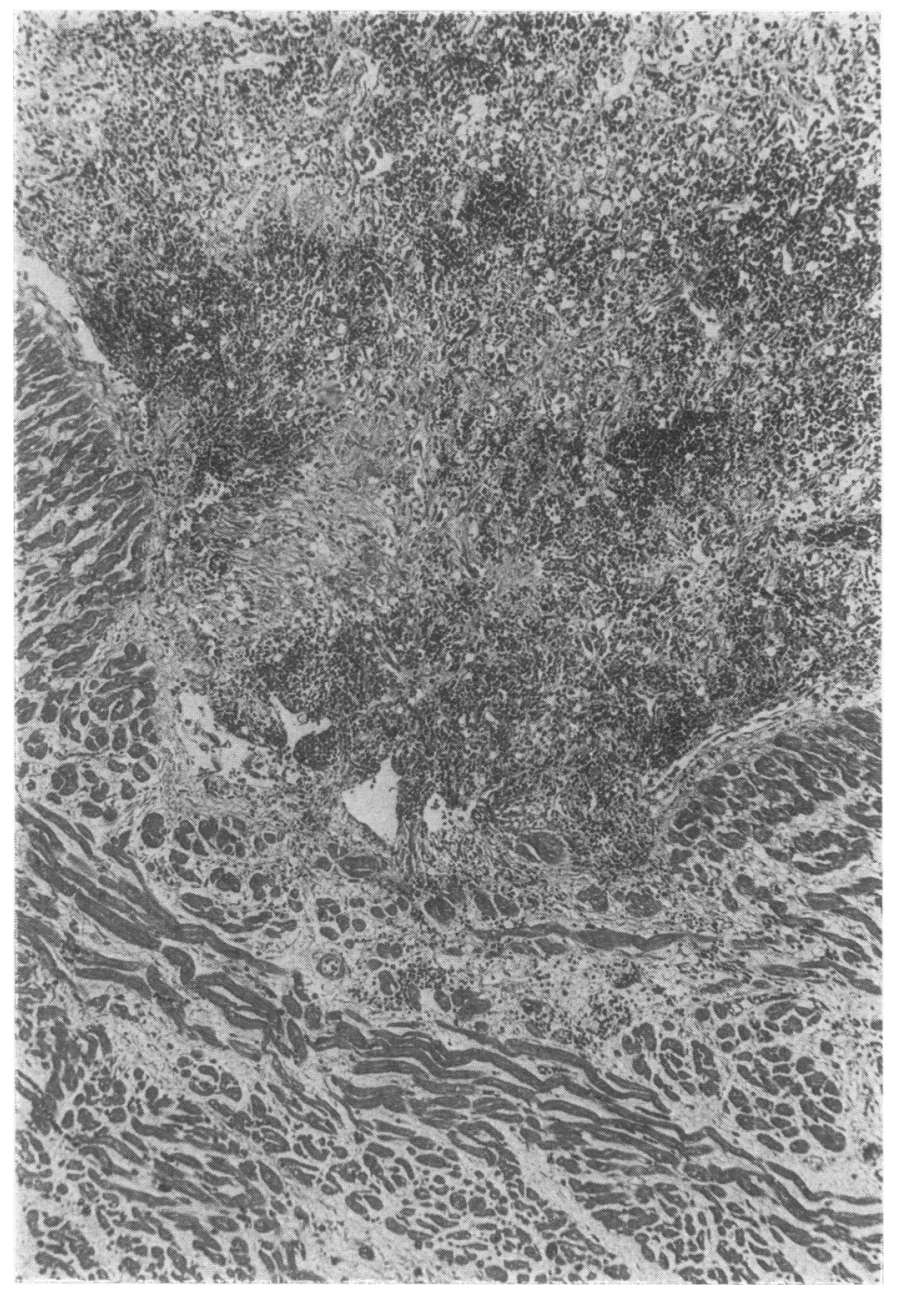

Section of right ventricle. Note large, well-organised thrombus occupying right ventricular cavity, densely adherent to right ventricle in several areas with extension of fibrous bands into ventricular wall (Haematoxylin and eosin $\times 63$ ).

\section{Discussion}

The ventricular mural thrombus present in our patient represents an unusual complication of myocardial sarcoidosis that has been reported in only six of the over 150 necropsy cases of myocardial sarcoidosis published. This low prevalence is in pronounced contrast to the idiopathic cardiomyopathies, in which the prevalence of mural thrombosis is as high as $75 \%$ (Roberts and Ferrans, 1975).

The major factors contributing to ventricular clot formation are stasis of blood flow and endocardial injury (Roberts and Ferrans, 1975). Clinically, mural thrombi are usually associated with congestive heart failure. It is significant that only $20-30 \%$ of patients with fatal myocardial sarcoidosis present with congestive heart failure.
Death in this disorder, as was probably the case with our patient, is most often the result of an arrhythmia and may occur in the absence of diffuse ventricular wall involvement. This in part may explain the low prevalence of mural thrombosis in this disease.

Our patient was atypical in that she showed no clinical evidence of congestive heart failure, and because her right ventricle was only slightly'dilated at post-mortem examination. Five of the six previously reported patients with sarcoidosis and mural thrombosis had congestive heart failure and all six had some degree of cardiac dilatation. In three of these patients the thrombus was exclusively in the left ventricle (Johnson and Jason, 1944; Powell, 1954; Harthorne and Freiman, 1975) and in one case the thrombus was found in the left atrial appendage (Deneberg, 1965). In the 
single case where the thrombus was present exclusively in the right ventricle, there was appreciable thinning of the right ventricular wall with replacement by collagenous tissue, virtual absence of muscle fibres, and appreciable thickening of the endocardium (Clark and Blount, 1966). In the only case with bilateral thrombi the right ventricle was slightly dilated and showed focal scarring (Roberts and Ferrans, 1975).

Systemic and pulmonary emboli associated with mural thrombi have been reported to occur in three of the six previously reported cases as well as our own patient. Despite the low prevalence of mural thrombosis, it is important to recognise that this complication can occur in patients with sarcoidosis, especially if there are other findings suggesting cardiac involvement.

\section{References}

Clark, E J, and Blount, A W (1966). A fatal case of myocardial sarcoidosis. Lancet, 86, 568-570.

Deneberg, M (1965). Sarcoidosis of the myocardium and aorta. A case report. American Journal of Clinical Pathology, 43, 445-449.

Harthorne, J W, and Freiman, D G (1975). Case records of the Massachusetts General Hospital. New England Journal of Medicine, 293, 1140-1145.

Johnson, J B, and Jason, R S (1944). Sarcoidosis of the heart. Report of a case and review of the literature. American Heart Journal, 27, 246-258.

Powell, L W (1954). Sarcoidosis of the myocardium. North Carolina Medical Journal, 15, 28-32.

Roberts, W C, and Ferrans, V J (1975). Pathologic anatomy of the cardiomyopathies. Human Pathology, 6, 287-342.

Requests for reprints to: Dr James Wynne, Division of Pulmonary Medicine, University of Florida College of Medicine, Box J-225, J Hillis Miller Health Center, Gainesville, Florida 32610. 